\title{
Coagulase-Negative Staphylococci Clones Are Widely Distributed in the Hospital and Community
}

\author{
Luiza Pinheiro-Hubinger ${ }^{1,2}{ }^{\mathbb{D}}$, Danilo Flávio Moraes Riboli ${ }^{1}$, Lígia Maria Abraão ${ }^{1}$, \\ Eliane Patricia Lino Pereira Franchi ${ }^{1}$ and Maria de Lourdes Ribeiro de Souza da Cunha ${ }^{1, * \mathbb{D}}$ \\ 1 Department of Chemical and Biological Sciences, Microbiology and Immunology Sector, Institute of \\ Biosciences of Botucatu, Universidade Estadual Paulista-UNESP, Botucatu 18618-970, Brazil; \\ 1.pinheiro@unesp.br (L.P.-H.); danilo.riboli@ibb.unesp.br (D.F.M.R.); ligia.abraao@ymail.com (L.M.A.); \\ fliane24@yahoo.com.br (E.P.L.P.F.) \\ 2 Department of Anatomic Pathology, Instituto Lauro de Souza Lima, Bauru 17034-971, Brazil \\ * Correspondence: mlrs.cunha@unesp.br
}

check for updates

Citation: Pinheiro-Hubinger, L.; Moraes Riboli, D.F.; Abraão, L.M.; Pereira Franchi, E.P.L.; Ribeiro de Souza da Cunha, M.d.L.

Coagulase-Negative Staphylococci Clones Are Widely Distributed in the Hospital and Community. Pathogens 2021, 10, 792. https://doi.org/ $10.3390 /$ pathogens 10070792

Academic Editor: Jilei Zhang

Received: 21 April 2021

Accepted: 14 May 2021

Published: 23 June 2021

Publisher's Note: MDPI stays neutral with regard to jurisdictional claims in published maps and institutional affiliations.

Copyright: (c) 2021 by the authors. Licensee MDPI, Basel, Switzerland. This article is an open access article distributed under the terms and conditions of the Creative Commons Attribution (CC BY) license (https:/ / creativecommons.org/licenses/by/ $4.0 /)$.

\begin{abstract}
Coagulase-negative staphylococci (CoNS) may be considered contaminants when isolated from clinical specimens but may also be a cause of true infection. This study aimed to compare the clonality and SCCmec type of a collection of CoNS isolated from blood cultures of inpatients, nasal swabs of healthy individuals, and patients with chronic wounds, all from the same community, using SCCmec typing, pulsed-field gel electrophoresis (PFGE), and MLST. Staphylococcus epidermidis, exhibited high clonal diversity, but hospital and community clusters were observed. Nosocomial S. epidermidis clones belonged to sequence types ST2, ST6, and ST23. Some Staphylococcus haemolyticus clones were found to circulate in the hospital and community, while Staphylococcus saprophyticus exhibited very high clonal diversity. Staphylococcus lugdunensis, Staphylococcus warneri, and Staphylococcus capitis revealed several isolates belonging to the same clone in the hospital and community. The detection of different SCCmec types within the same cluster indicated high diversity. S. epidermidis was associated with SCCmec I and III, S. haemolyticus with I and II, S. capitis with type V, Staphylococcus hominis with mec complex type A and ccr1, and S. warneri and S. saprophyticus with SCCmec I. The generation of elements and new combinations of cassette genes were highly associated with CoNS isolates, suggesting that SCCmec may not be a good marker of clonality in these bacteria.
\end{abstract}

Keywords: coagulase-negative staphylococci; SCCmec; PFGE; MLST

\section{Introduction}

Coagulase-Negative Staphylococci (CoNS) are colonizers of human and animal skin and mucosa [1-3]. The group of CoNS is composed of several species, including Staphylococcus epidermidis, Staphylococcus haemolyticus, Staphylococcus saprophyticus, Staphylococcus capitis, Staphylococcus warneri, Staphylococcus hominis, Staphylococcus lugdunensis, Staphylococcus simulans, Staphylococcus caprae, Staphylococcus cohnii, Staphylococcus xylosus, and Staphylococcus schleiferi [4]. Although they live in symbiosis with their host, CoNS can cause important infections in case of breakdown of the skin barrier [4]. Therefore, CoNS are considered essentially opportunistic agents that use organic situations to produce serious infections [3,5]. The pathogenic potential of CoNS is mainly related to some virulence factors, especially biofilm, but also toxins and antimicrobial resistance. Some criteria are used to determine if a CoNS is a true cause of infection, such as absence of infection caused by another microorganism, presence of two or more isolates of the same species, improvement of symptoms after therapy, presence of foreign body, time for positivity less than 16 hours, and antibiotic resistance [6,7]. It is a known fact that CoNS infections may be seriously impacted by antimicrobial resistance.

Antimicrobial resistance is a global challenge for the treatment of infections caused by staphylococci and other bacteria, especially hospital-acquired infections. The esti- 
mated prevalence of methicillin resistance is $20 \%$ among community isolates [8] and more than $80 \%$ among hospital isolates [9]. This resistance is usually mediated by a modified penicillin-binding protein 2 (PBP2), which is encoded by the mecA gene. The gene is carried by a mobile genetic element, the staphylococcal chromosome cassette mec (SCCmec), which is considered a vehicle for the exchange of resistance factors between CoNS and $S$. aureus [10]. In addition, SCCmec is used to characterize the phylogenetic relationship among Staphylococcus isolates.

The molecular typing of hospital S. epidermidis isolates using different tools has shown considerable diversity within this species [11]. Pulsed-field gel electrophoresis (PFGE) is widely used in studies investigating the local clonality of bacterial strains and is efficient in identifying staphylococcal profiles. Studies using Multilocus Sequence Typing (MLST) have shown that the population structure of S. epidermidis in hospitals is composed of a main lineage with high genetic diversity, clonal complex 2 (CC2) [12-14]. The combination of SCCmec and PFGE profiling has provided short- and long-term epidemiological data that are consistent with the results of MLST [14]. However, little is known about the clonal diversity of non-epidermidis CoNS species or about colonization CoNS isolates and their clonal relationship with isolates from infection sites.

Therefore, this study aimed to evaluate the clonal profile and SCCmec type of S. epidermidis, S. haemolyticus, S. hominis, S. warneri, S. capitis, S. lugdunensis, S. saprophyticus, Staphylococcus pasteuri, S. simulans, S. xylosus, and S. cohnii isolated from blood cultures of hospital inpatients, nasal swabs of healthy individuals, and patients with chronic wounds attending basic health units, all from the same community.

\section{Results}

The following species were isolated from nasal swabs: 57 (39.3\%) S. epidermidis, 18 (11.7\%) S. haemolyticus, 27 (17.5\%) S. warneri, 19 (12.3\%) S. lugdunensis, 5 (3.2\%) S. capitis, $12(7.8 \%)$ S. saprophyticus, $2(1.3 \%)$ S. simulans, $3(2 \%)$ S. pasteuri, $1(0.6 \%)$ S. xylosus, and $1(0.6 \%)$ S. cohnii.

Among the wound isolates, we identified 3 (13.6\%) S. epidermidis, 7 (31.8\%) S. haemolyticus, $5(22.7 \%)$ S. warneri, 1 (4.5\%) S. hominis, 1 (4.5\%) S. lugdunensis, 1 (4.5\%) S. simulans, $2(9 \%)$ S. capitis, and $2(9 \%)$ S. saprophyticus. The blood culture isolates included $40(30.3 \%)$ S. epidermidis, $28(21.2 \%)$ S. haemolyticus, 7 (31.8\%) S. warneri, $22(16.7 \%)$ S. hominis, $10(7.6 \%)$ S. lugdunensis, and 25 (19\%) S. capitis.

Figures 1-8 show the dendrograms of PFGE types for S. epidermidis, S. haemolyticus, S. warneri, S. hominis, S. lugdunensis, S. capitis, S. saprophyticus, and S. pasteuri, respectively. The similarity of the three $S$. simulans strains was less than $60 \%$ (threshold was $>80 \%$ ), and these isolates are therefore not represented in a dendrogram.

A total of $185(62 \%)$ isolates were positive for the mec $A$ gene, including 48 from the community collection (33\%), 21 from wounds (100\%), and 116 from blood cultures (88\%). Table 1 shows the number and percentage of SCCmec types according to sampling site. The results for the non-typable isolates (cases in which only the internal control for mecA was amplified in Protocol 2 are not shown) are presented in Table 2.

Table 1. SCCmec types according to sampling site.

\begin{tabular}{cccc}
\hline SCCmec & Nasal Colonization & Wounds & Blood Cultures \\
\hline I & $25(52)$ & $9(42.8)$ & $32(27.6)$ \\
II & $1(2)$ & 0 & $1(0.9)$ \\
III & $3(6.25)$ & 0 & $9(7.8)$ \\
IV & $1(2)$ & 0 & $9(7.8)$ \\
V & $3(6.25)$ & 0 & $12(10.3)$ \\
I, III & $4(8.3)$ & 0 & $16(13.8)$ \\
I, II & $3(6.25)$ & $4(19)$ & $6(5.2)$ \\
III, IV & 0 & 0 & $9(7.8)$ \\
VIII & $1(2)$ & $8(38)$ & 0 \\
NT & $7(14.6)$ & $1(4.5)$ & $21(18.1)$ \\
mecA negative & $97(67)$ & $22(100)$ & $16(12.1)$ \\
Total & $145(100)$ & & $132(100)$ \\
\hline
\end{tabular}




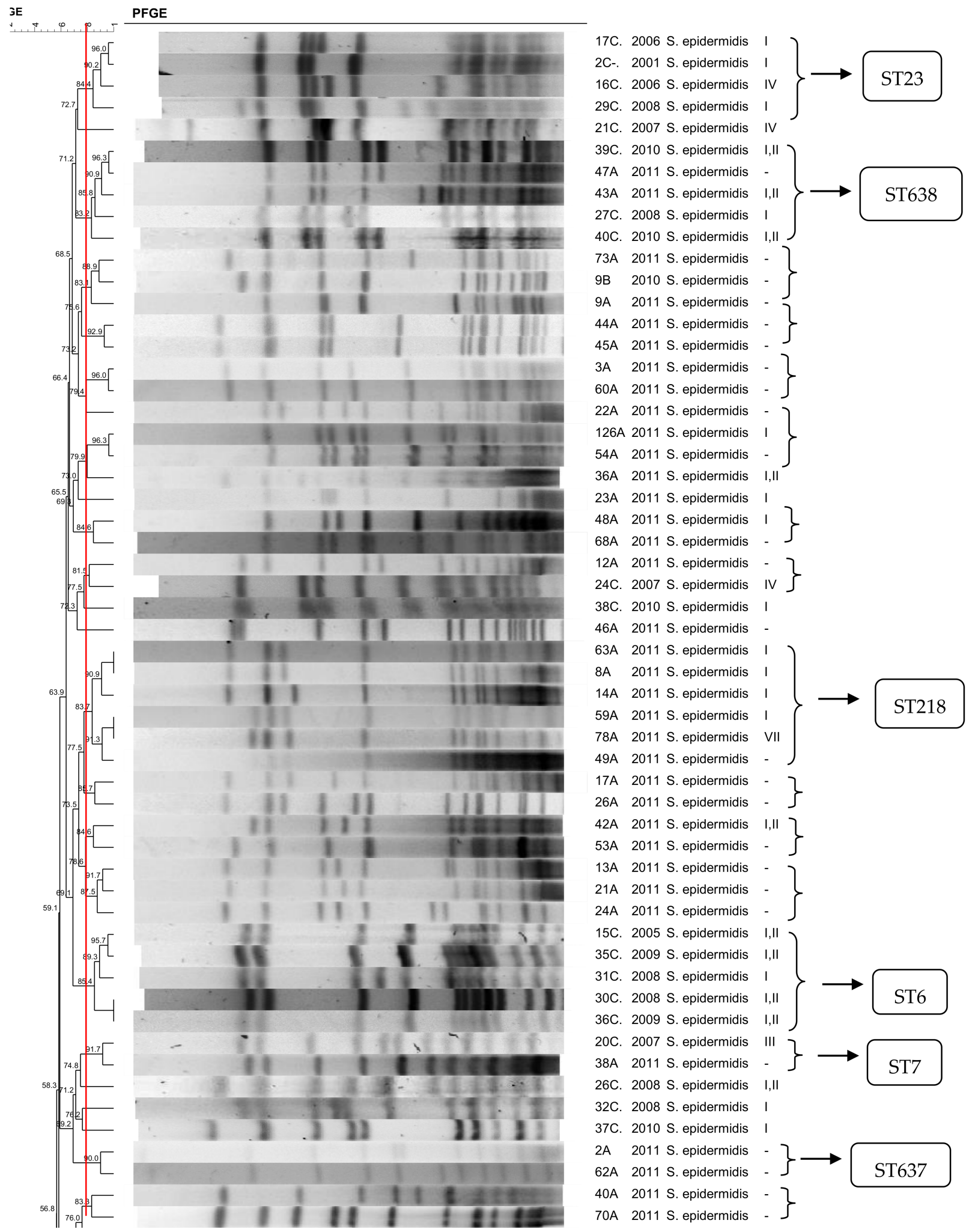

Figure 1. Cont. 

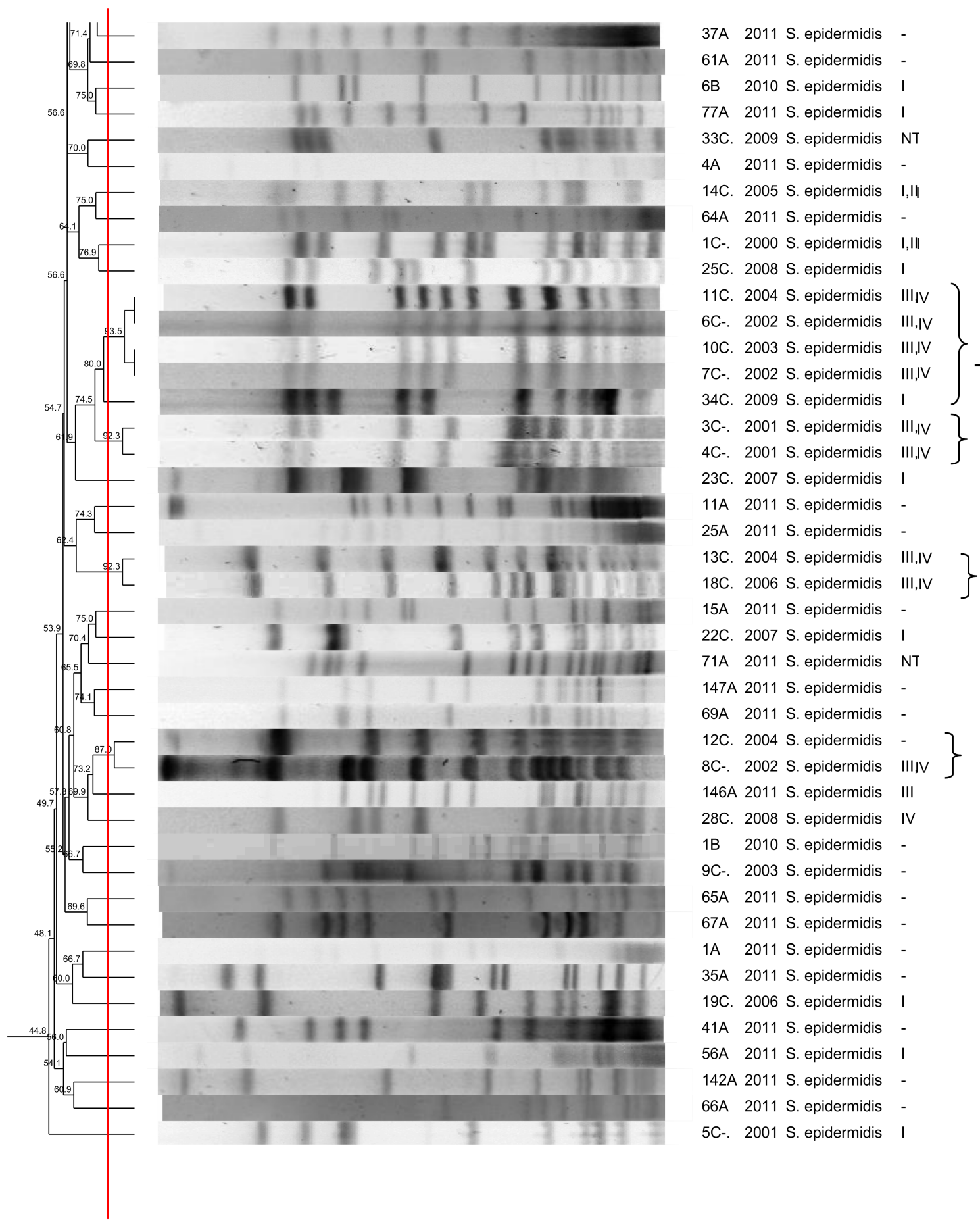

Figure 1. Dendrogram generated by Dice/UPGMA analysis (Bionumerics Applied Maths), from PFGE-SmaI profiles of S. epidermidis isolated from nasal swabs (A), wounds (B), and blood cultures (C). Square brackets highlight the clusters ( $>80 \%$ similarity). Roman numerals represent the SCCmec type. 


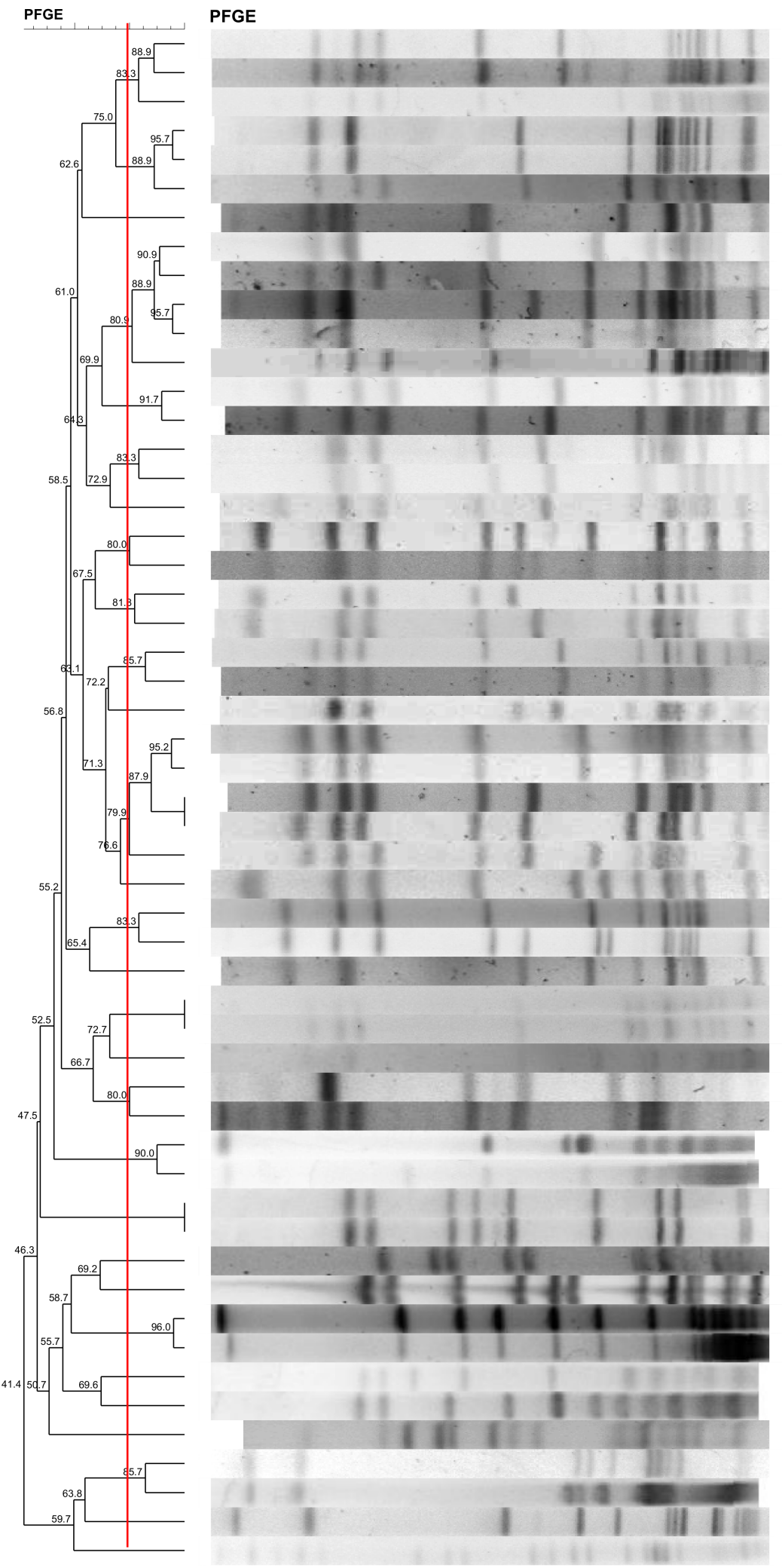

$\left.\begin{array}{llll}\text { 19B } & 2010 & \text { S. haemolyticus } & \text { I,II } \\ \text { 20B } & 2010 & \text { S. heemolyticus } & \text { I,II } \\ \text { 5A } & 2011 & \text { S. haemolyticus } & \text { I,II }\end{array}\right\}$

Figure 2. Dendrogram generated by Dice/UPGMA analysis (Bionumerics Applied Maths), from PFGE-SmaI profiles of S. haemolyticus isolated from nasal swabs (A), wounds (B), and blood cultures (C). Square brackets highlight the clusters (>80\% similarity). Roman numerals represent the SCCmec type. 


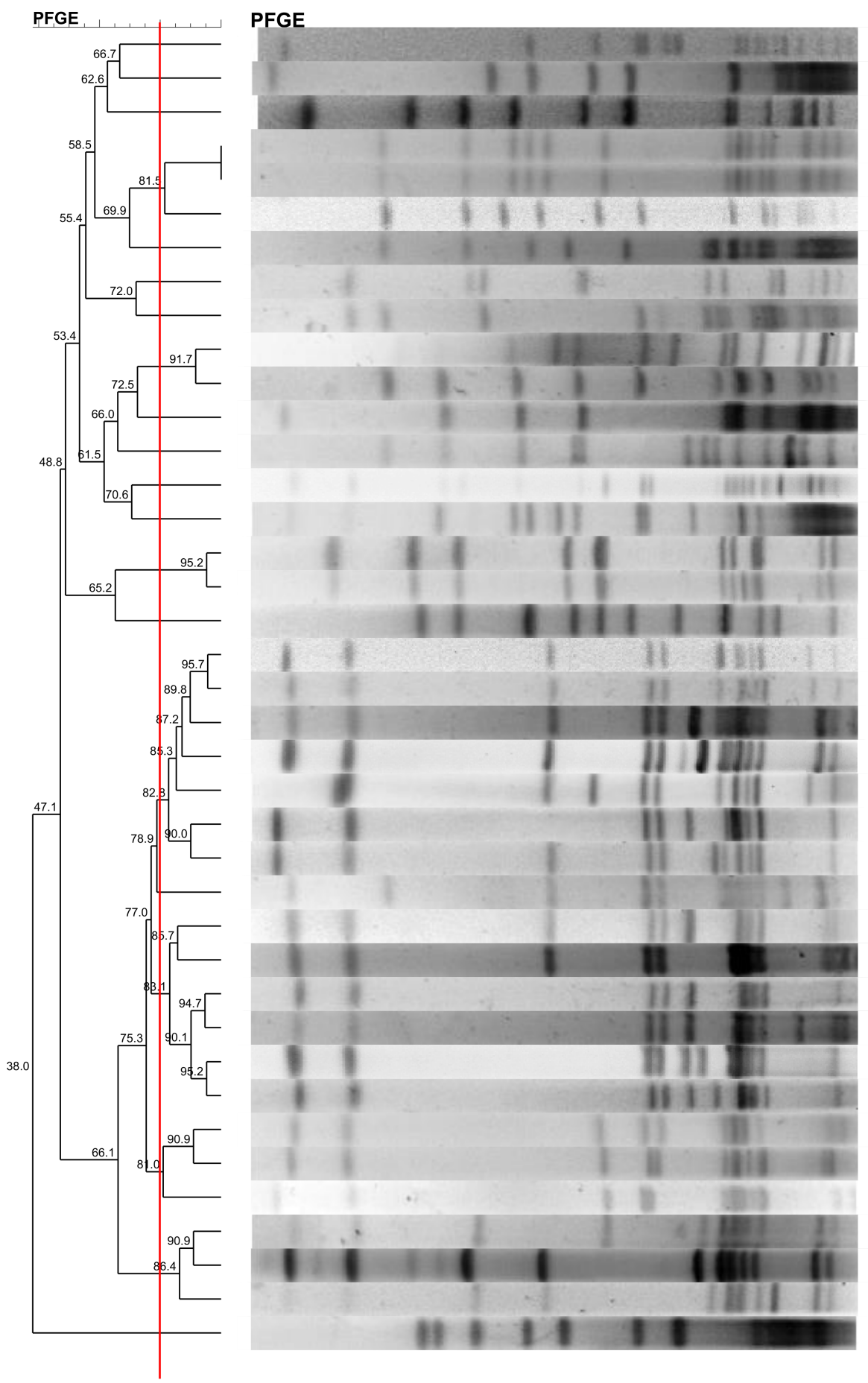

127C 2010 S. warneri NT 102A 2011 S. warneri 126C 1992 S. warneri 132A 2011 S. warneri 131A 2011 S. warneri I 116C 2010 S. warneri 92A 2011 S. warneri 112C 2009 S. warneri I 88A 2011 S. warneri I 11B 2010 S. warneri I 96A 2011 S. warneri - $\}$ 51A 2011 S. warneri 55A 2011 S. warneri 148A 2011 S. warneri I,II 7A 2011 S. warneri 15B 2010 S. warneri - ? 111A 2011 S. warneri NT $\}$ 80A 2011 S. warneri 117C 2001 S. warneri - ) 115C 2001 S. warneri NT 90A 2011 S. warneri 152A 2011 S. warneri 21B 2010 S. warneri 82A 2011 S. warneri 79A 2011 S. warneri 87A 2011 S. warneri 140A 2011 S. warneri 93A 2011 S. warneri I 113C 1991 S. warneri 94A 2011 S. warneri 151A 2011 S. warneri 114C 1994 S. warneri - J 112A 2011 S. warneri 135A 2011 S. warneri 84A 2011 S. warneri - J 106A 2011 S. warneri NT 133A 2011 S. warneri । 22B 2010 S. warneri - J 34A 2011 S. warneri -

Figure 3. Dendrogram generated by Dice/UPGMA analysis (Bionumerics Applied Maths), from PFGE-SmaI profiles of S. warneri isolated from nasal swabs (A), wounds (B), and blood cultures (C). Square brackets highlight the clusters (>80\% similarity). Roman numerals represent the SCCmec type. 

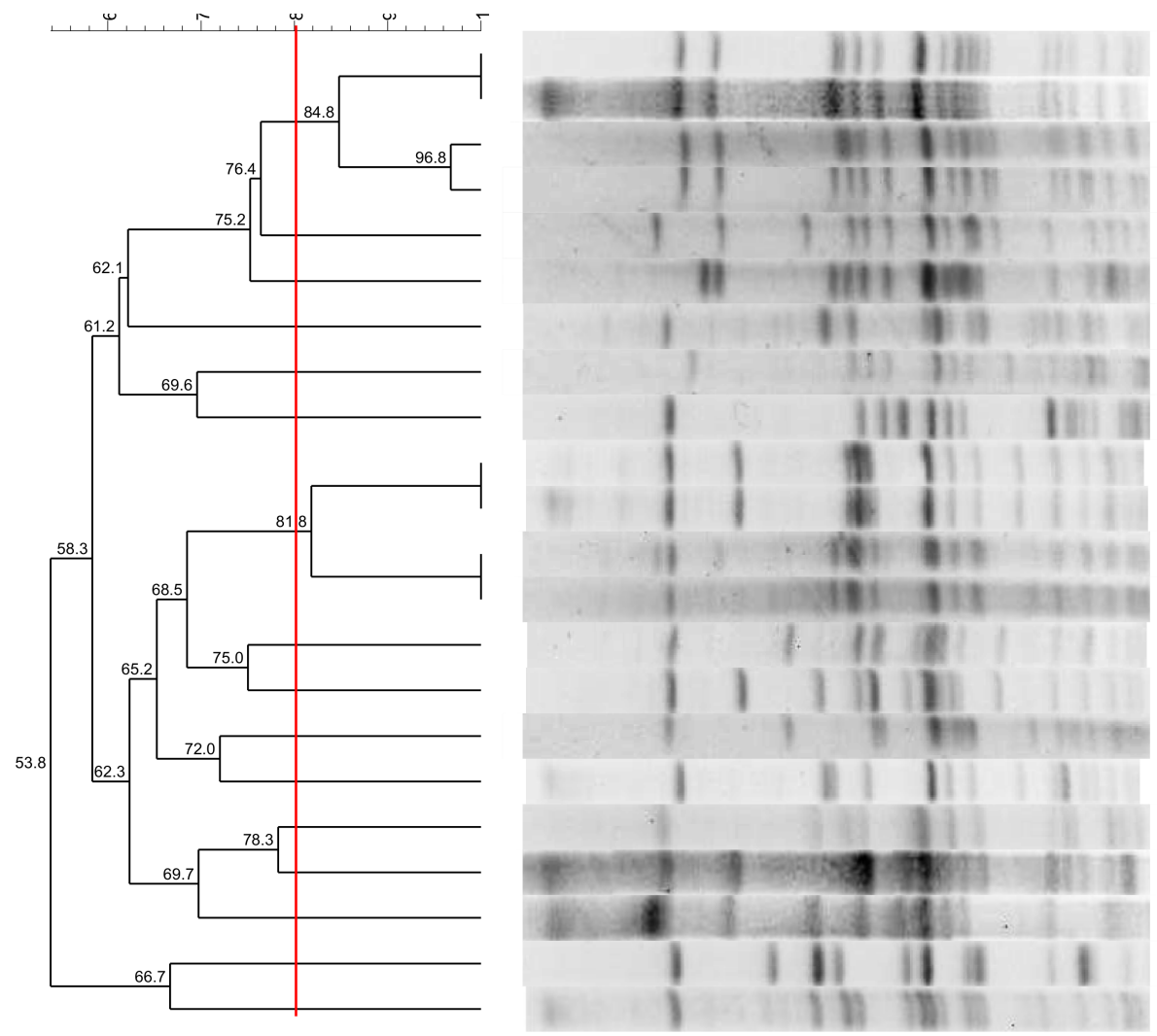

$\left.\begin{array}{llll}\text { 87C } & 2003 & \text { S. hominis I } \\ 97 C & 2003 & \text { S. hominis } & \text { NT } \\ 85 C & 2007 & \text { S. hominis II } \\ \text { 88C } & 2009 & \text { S. hominis } & \text { III }\end{array}\right\}$

Figure 4. Dendrogram generated by Dice/UPGMA analysis (Bionumerics Applied Maths), from PFGE-XhoI profiles of S. hominis isolated from wounds (B), and blood cultures (C). Square brackets highlight the clusters ( $>80 \%$ similarity).

Table 2. Amplification products detected in mecA-positive isolates without the mec or ccr complex or complex multiplicity.

\begin{tabular}{ccccc}
\hline Isolate & Species & Protocol 2 & & \\
\hline $78 \mathrm{~A}$ & S. epidermidis & $\mathrm{IC}$ & ccr & mec \\
$83 \mathrm{C}$ & S. hominis & + & $1+4$ & $\mathrm{~A}$ \\
$93 \mathrm{C}$ & S. hominis & + & 1 & $\mathrm{~A}$ \\
$116 \mathrm{C}$ & S. warneri & + & 1 & $\mathrm{~A}$ \\
$139 \mathrm{C}$ & S. capitis & + & $1+4+5$ & - \\
\hline
\end{tabular}

$\overline{\mathrm{IC}}=$ internal control for $m e c A .+=$ positive, $-=$ negative.

Some clones were chosen for the MLST analyses, including (i) the largest clones containing the largest number of strains, (ii) a cluster formed by a colonization isolate and a clinical isolate, and (iii) a colonization clone. The sequence types are presented in Figure 1. Two strains (2A and 47A) exhibited a new profile and were named sequence types ST637 and ST638, respectively. Table 3 shows the diversity indexes based on the clonal profiles. The higher the diversity index, the less similar are the strains from that specific group. 


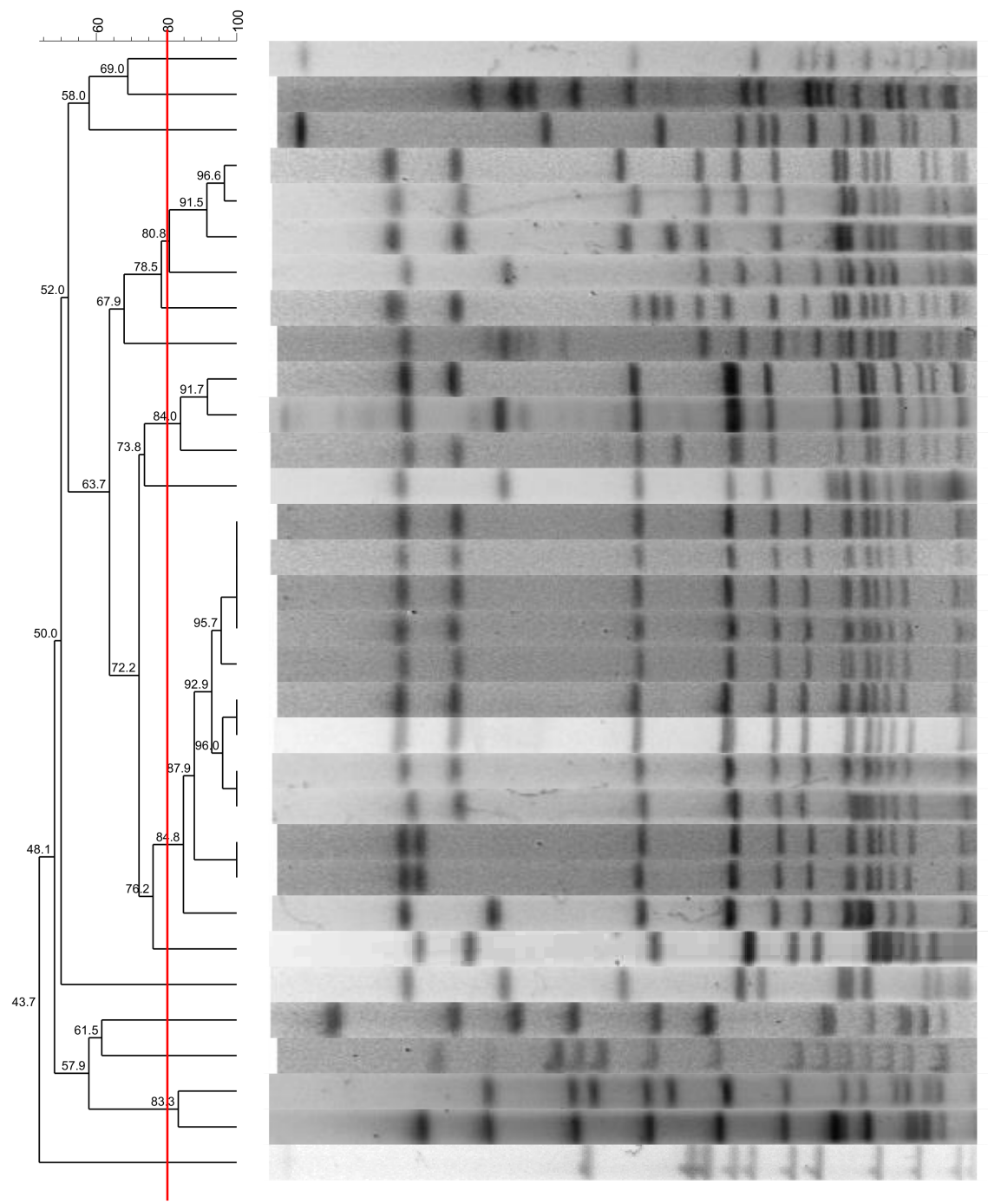

$\left.\begin{array}{llll}\text { 140C } & .2012 & \text { S. capitis } & \text { VI } \\ \text { 128C } & .2012 & \text { S. capitis } & \text { IV } \\ \text { 135C } & .2012 & \text { S. capitis } & \text { V } \\ 139 C & .2012 & \text { S. capitis } & \text { NT } \\ \text { 141C } & .2012 & \text { S. capitis } & \text { III } \\ \text { 143C } & .2012 & \text { S. capitis } & \text { III } \\ \text { 145C } & .2012 & \text { S. capitis } & \text { IV }\end{array}\right\}$

Figure 5. Dendrogram generated by Dice/UPGMA analysis (Bionumerics Applied Maths), from PFGE-SmaI profiles of S. capitis isolated from nasal swabs (A), wounds (B), and blood cultures (C). Square brackets highlight the clusters ( $>80 \%$ similarity). Roman numerals represent the SCCmec type.

Table 3. Diversity index of the CoNS species.

\begin{tabular}{cc}
\hline Species & Diversity Index \\
\hline S. epidermidis & 0.971026 \\
S. haemolyticus & 0.984708 \\
S. warneri & 0.981087 \\
S. hominis & 0.995717 \\
S. capitis & 0.969416 \\
S. lugdunensis & 0.977062 \\
S. saprophyticus & 0.999598 \\
S. pasteuri & 0.999598 \\
\hline
\end{tabular}




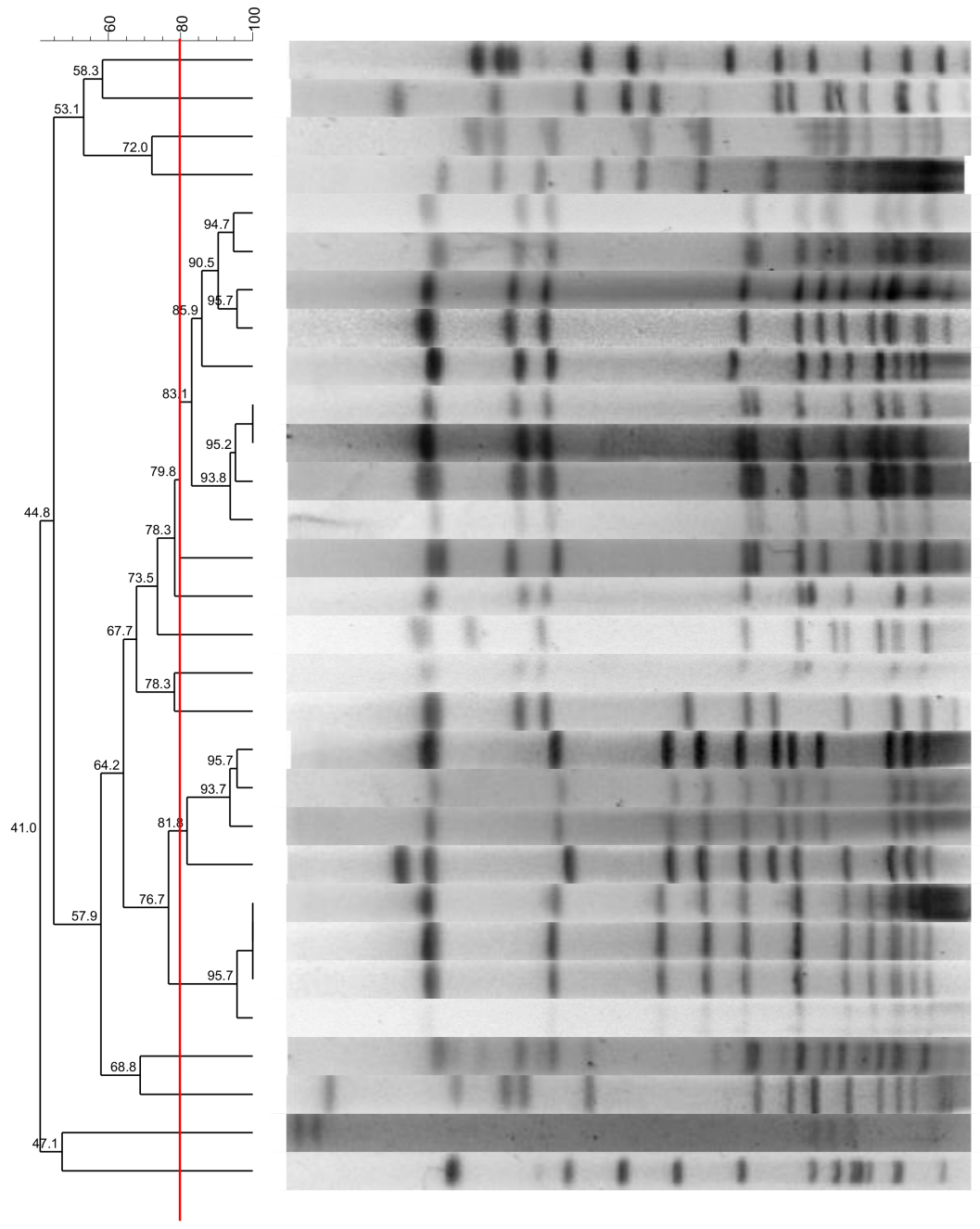

\begin{tabular}{|c|c|c|}
\hline $118 \mathrm{~A}$ & $2011 \mathrm{~S}$. lugdunensis & \\
\hline 12B & $2010 \mathrm{~S}$. lugdunensis & \\
\hline 145A & 2011 S. lugdunensis & I,III \\
\hline $39 \mathrm{~A}$ & 2011 S. lugdunensis & - \\
\hline $57 \mathrm{~A}$ & 2011 S. lugdunensis & - \\
\hline 97A & 2011 S. lugdunensis & NT \\
\hline $125 \mathrm{~A}$ & 2011 S. lugdunensis & - \\
\hline $157 \mathrm{~A}$ & 2011 S. lugdunensis & - \\
\hline $111 \mathrm{C}$ & 2009 S. lugdunensis & - \\
\hline $110 \mathrm{C}$ & $1998 \mathrm{~S}$. lugdunensis & - \\
\hline 137A & 2011 S. lugdunensis & - \\
\hline $103 \mathrm{~A}$ & 2011 S. lugdunensis & - \\
\hline 107A & 2011 S. lugdunensis & NT \\
\hline $120 \mathrm{~A}$ & $2011 \mathrm{~S}$. lugdunensis & \\
\hline $108 \mathrm{C}$ & 1997 S. lugdunensis & - \\
\hline $103 \mathrm{C}$ & $1990 \mathrm{~S}$. lugdunensis & - \\
\hline $106 \mathrm{C}$ & 1996 S. lugdunensis & NT \\
\hline $74 \mathrm{~A}$ & 2011 S. lugdunensis & \\
\hline $107 \mathrm{C}$ & 2009 S. lugdunensis & - \\
\hline $99 \mathrm{~A}$ & $2011 \mathrm{~S}$. lugdunensis & NT \\
\hline $117 \mathrm{~A}$ & 2011 S. lugdunensis & - \\
\hline $161 \mathrm{~A}$ & 2011 S. lugdunensis & $\mathrm{I}, \mathrm{II}$ \\
\hline $18 \mathrm{~A}$ & $2011 \mathrm{~S}$. lugdunensis & - \\
\hline $75 \mathrm{~A}$ & $2011 \mathrm{~S}$. lugdunensis & - \\
\hline $76 \mathrm{~A}$ & 2011 S. lugdunensis & - \\
\hline $105 \mathrm{C}$ & $1997 \mathrm{~S}$. lugdunensis & - \\
\hline $100 \mathrm{~A}$ & 2011 S. lugdunensis & - \\
\hline $118 \mathrm{C}$ & 2008 S. lugdunensis & III \\
\hline $102 \mathrm{C}$ & 2002 S. lugdunensis & - \\
\hline $109 \mathrm{C}$ & $2009 \mathrm{~S}$. lugdunensis & - \\
\hline
\end{tabular}

Figure 6. Dendrogram generated by Dice/UPGMA analysis (Bionumerics Applied Maths), from PFGE-SmaI profiles of S. lugdunensis isolated from nasal swabs (A), wounds (B), and blood cultures (C). Square brackets highlight the clusters ( $>80 \%$ similarity). Roman numerals represent the SCCmec type.
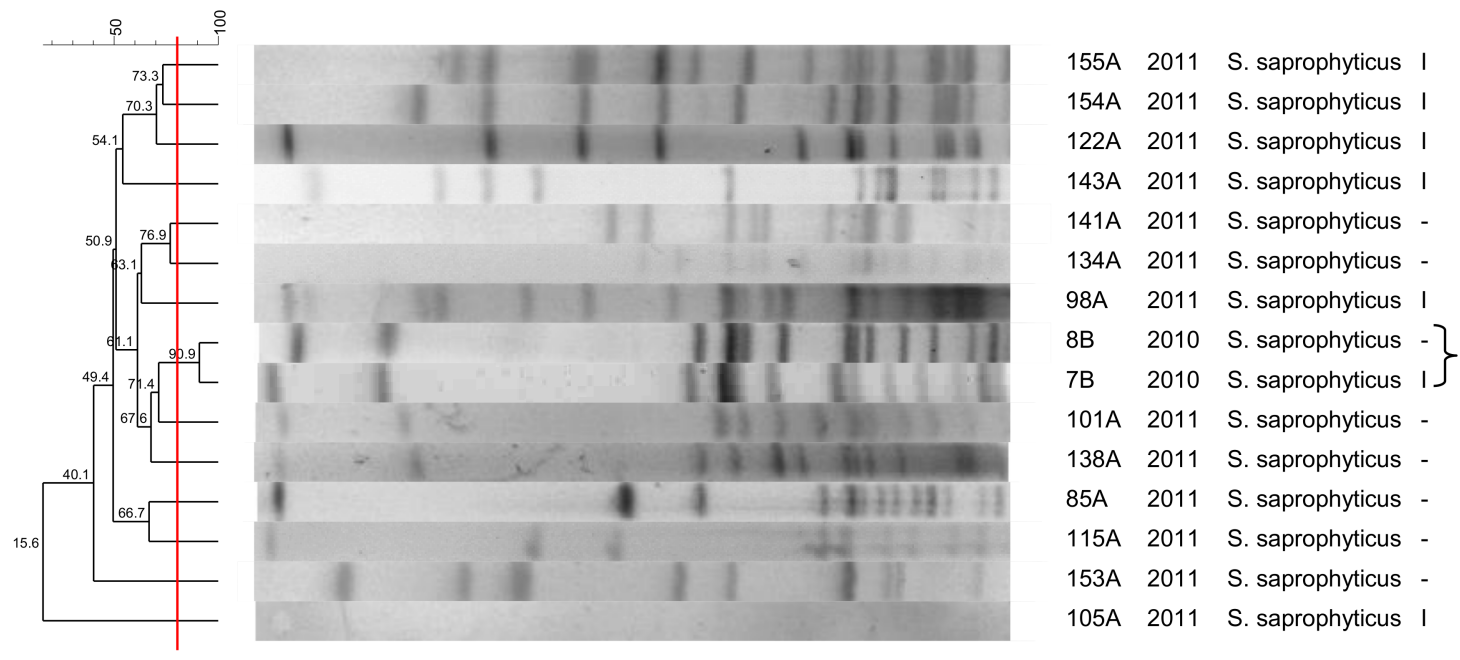

Figure 7. Dendrogram generated by Dice/UPGMA analysis (Bionumerics Applied Maths), from PFGE-SmaI profiles of S. saprophyticus isolated from nasal swabs (A) and wounds (B). Square brackets highlight the clusters ( $>80 \%$ similarity). Roman numerals represent the SCCmec type. 

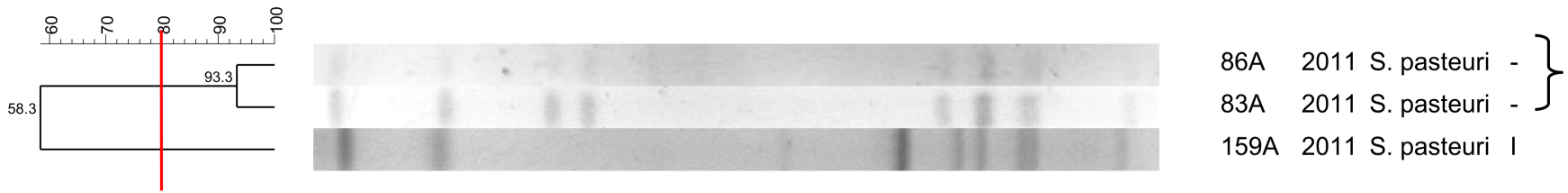

Figure 8. Dendrogram generated by Dice/UPGMA analysis (Bionumerics Applied Maths), from PFGE-SmaI profiles of S. pasteuri isolated from nasal swabs (A). Square brackets highlight the clusters ( $>80 \%$ similarity). Roman numerals represent the SCCmec type.

\section{Discussion}

This study aimed to compare clinical, commensal, and wound CoNS strains in order to evaluate the clonal connection of isolates belonging to different species and of different origins. This type of study is the first step to understand the diversity of a species collection and to determine the linkage between subpopulations of strains, especially between colonization and infection isolates, or between susceptible and resistant strains [15].

Due to being isolated from several clinical specimens, CoNS may be wrongly described as contaminants, despite being the true cause of infection in many cases. Diverse clinical and microbiological factors are used to classify CoNS as true causes of infection or as contaminants [16]. Some studies show high antimicrobial resistance rates as factors associated with CoNS causing infection [16].

\subsection{S. epidermidis}

The S. epidermidis isolates comprised a highly diverse collection of strains, both in the hospital and in the community, as reported previously [17-20], despite the presence of three hospital clusters, some clones in the community, and one cluster including blood culture and nasal isolates. Isolates of the last cluster were typed by MLST and belonged to a new ST638, closely related to ST151 and ST228. This finding suggests evolutive advantages of this clone, allowing its circulation between the hospital and community [12].

Clones composed of hospital isolates belonged to ST2, ST6, and ST23. ST23 has been associated with linezolid resistance, carrying mutations in the 23S rRNA gene as well as the cfr plasmid [21-25]. ST2 has been described in clinical and colonization isolates [12,21,26] but is more frequently found in hospital strains [16]. ST6 is often observed in clinical and colonization isolates [11] and is one of the main types among hospital isolates [13]. In the present study, ST6 was associated with SCCmec I and III, in contrast to a previous study in which ST6 was associated with SCCmec II and V [13], as well as with linezolid resistance [27].

One strain clustered to a hospital-community clone belonged to ST7, a sequence type that has been associated with SCCmec IV [21], close to the hospital-community interface. As in the present work, susceptibility of ST7 to methicillin has been reported [16]. Two community clones were identified as ST218 and ST637. In a previous study, ST218 was described in S. epidermidis causing bloodstream infection [28].

\subsection{S. haemolyticus}

The S. haemolyticus isolates exhibited some clonal diversity, forming small clusters. One cluster contained seven hospital strains, another contained two commensal and two wound strains, and one cluster contained one blood culture and one wound isolate. The chronic wound isolates were genetically related to nosocomial and commensal strains, highlighting their opportunistic role. Indeed, the high plasticity of S. haemolyticus was demonstrated by genome sequencing, which revealed a high frequency of insertion sequences and transposons [29]. The high clonal diversity of S. haemolyticus has also been described in previous studies $[20,30]$. Occasionally, certain $S$. haemolyticus clones may predominate over others in the hospital [31]. Their genomic plasticity seems to contribute to the heterogeneity of the species, and small clones may appear at close locations within the hospital or 
community, but circulation within and between these environments does not seem to be common.

\subsection{S. hominis}

S. hominis was the only CoNS isolate that was not properly restricted by SmaI. Bouchami et al. [32] observed the same phenomenon, as well as low clonality of this species. Our results show high diversity of $S$. hominis within the hospital, despite the presence of a clone circulating for 7 years and another for 3 years. However, most strains seem to originate from the patient's microbiota. Comparison with S. hominis isolated from healthy individuals outside the hospital would permit a better understanding of the diversity of this species. The absence of S. hominis in nasal swabs is a limitation of the study.

A high prevalence of SCCmec III in S. hominis has been reported in Brazil [33]. In the present study, $20 \%$ of isolates with non-typed SCCmec carried mec complex type A and ccr1, as previously reported [32,34]. The high frequency of the mecA complex suggests that S. hominis may be a reservoir of this element.

\subsection{S. saprophyticus}

Nasal isolates of S. saprophyticus did not form clusters. The two S. saprophyticus strains isolated from the wounds of two patients exhibited a similar profile. On the other hand, Sousa et al. [35] showed high clonality of S. saprophyticus strains causing communityacquired urinary tract infections. Widerstrom et al. [36] found a very heterogeneous population consisting of several S. saprophyticus clones associated with urinary tract infection and the lack of a specific uropathogenic clone; however, there were clusters of highly related isolates. These data demonstrate a high diversity of this species among commensal isolates, with a low probability of causing infections. Certain genotypes may have biological advantages that facilitate their persistence as causes of infection. The same genotype found in different patients suggests a common source of contamination with this microorganism. However, it remains unclear which intrinsic bacterial factors facilitate infection.

\subsection{S. lugdunensis}

S. lugdunensis is less commonly isolated than other CoNS. When truly causing infection, the presence of $S$. lugdunensis is important since the course of infection is similar to that of S. aureus [37]. Staphylococcus lugdunensis is associated with increased symptomatic manifestation and a shorter interval between surgery and infection when compared to S. epidermidis and S. aureus [38]. Some authors suggest that any S. lugdunensis isolate should be considered a pathogen until proven otherwise [37].

The S. lugdunensis isolates formed two main clusters that contained commensal and clinical strains, with high similarity. The clustering of strains isolated within a period of up to 15 years suggests a low level of genetic diversity within this species, as shown previously $[15,39]$. The genetic structure of this population also implies that most commensal strains have the ability to cause infection, at least locally, or that hospital isolates may be spreading to the community, reaching the healthy population. Furthermore, the high similarity among the restriction patterns may also indicate that this is due to the intrinsic homogeneity of $S$. lugdunensis rather than to an epidemiological link among the isolates [15].

\subsection{S. warneri}

Although S. warneri is rarely isolated from human infections, this species was relatively common in the nasal and wound samples and less frequent in blood cultures. Species diversity was low, with some clusters including wound, nasal, and blood culture isolates. The observation of a PFGE type with several representatives demonstrates the circulation of a single clone in the hospital and community. Previous studies have shown a 
higher diversity of $S$. warneri [40] and the dissemination of a single clone among health professionals [41]. The paucity of molecular epidemiology studies involving S. warneri hinders understanding the clonality of this species. To our knowledge, there are no genetic studies involving a large collection of $S$. warneri strains, and our results may therefore contribute to a better understanding of $S$. warneri dissemination.

\subsection{S. capitis}

The heterogeneity of S. capitis was low among blood culture isolates. De Silva et al. [42], studying sepsis, blood culture contaminants, and colonization strains, found that all 29 S. capitis isolates belonged to one clone. However, the authors only evaluated inpatients.

In the present study, the same $S$. capitis clones colonizing community dwellers (nasal swabs) are probably also associated with hospital infections (blood cultures) and chronic wounds. These data confirm the high homogeneity of this species and the persistence of certain clones. A single clone that has been circulating from 2009 to 2012 might be associated with an outbreak of $S$. capitis involving patients with a positive blood culture and a wound infection. Staphylococcus capitis is not a common nosocomial pathogen and is rarely found in the microbiota of tested patients [43]. Nevertheless, this species is endemic in some neonatal units and has been associated with bloodstream infections [44].

\subsection{S. pasteuri}

Although the first description of this species is relatively recent, some studies have shown a high frequency among human and animal isolates [45,46]. Staphylococcus pasteuri is often misidentified as other species such as $S$. warneri [47]. Studies using sequencing of the $16 \mathrm{~S}$ rRNA or $r p o B$ gene report the presence of this species [45-47], while studies using biochemical tests or DNA amplification protocols may underestimate the presence of these isolates. In the present study, three unidentified strains were confirmed as S. pasteuri by $r p o B$ gene sequencing. Two of the S. pasteuri nasal isolates were clonally related, probably because of the low prevalence of this species. One isolate carried SCCmec type I, as reported previously [48]. However, further analysis is not possible due to the low number of isolates in the present study.

\subsection{S. simulans}

Previous studies have shown high clonality of S. simulans [22,49], mostly associated with antimicrobial resistance, and some report specific heterogeneity [45]. The small number of $S$. simulans in the present study limits conclusions regarding the phylogenetic relationship among isolates of this species.

\subsection{SCCmec}

Proposing a criterion for clone definition based on PFGE, SCCmec typing, and MLST, Miragaia et al. [14] suggested that the best approach is to use PFGE typing followed by SCCmec determination. In fact, in that study, isolates belonging to the same PFGE type carried distinct SCCmec types. Such differences were also found in our study and might be related to the use of two typing techniques. Clearly, the high rates of recombination and frequent acquisition of mobile genetic elements favor the occurrence of genomic polymorphisms [14] not only in S. epidermidis, but also in other CoNS isolates.

SCCmec could not be typed in a considerable part of the isolates due to the amplification of two or more types of $\mathrm{ccr} / \mathrm{mec}$ complexes, absence of amplification of one of the complexes, or combination of mec/ccr complexes that do not correspond to previously described types. Salgueiro et al. [26] observed $83 \%$ of S. epidermidis with non-typable SCCmec. The isolates with undetectable $c c r$ complex type 2 and mec were positively associated with strains from bloodstream infections. In the present study, a considerable number of colonizing strains exhibited this SCCmec profile. However, since the PCR detection method for the two complexes was used only in the isolates that were not typed by the protocol of Machado et al. [33], we cannot make such a correlation for our isolates. 
It is possible that the high recombination rates and the large number of element acquisition in CoNS [12,50], associated with high carriage rates of SCCmec [51], increase the potential for recombination into the cassette. In fact, analysis of the complete sequence of SCCmec by whole-genome sequencing of these strains with cassettes that are not typable by traditional amplification techniques would provide important data for the study of novel SCCmec types and recombination events.

In the study of Miragaia et al. [14], at least $18 \%$ of S. epidermidis isolates carried new SCCmec variants (non-typable elements or novel combinations of mec/ccr complexes), while other studies reported even higher frequencies [16,24]. In the present study, only one $S$. epidermidis isolate had a non-typed SCCmec, while most $S$. hominis and S. warneri isolates were not typable. This observation contrasts with descriptions for $S$. aureus in which few SCCmec types were identified in a large collection of isolates. The presence of similar regions in different SCCmec types indicates that the cassette has undergone several sequential events of recombination, giving rise to some structures resembling mosaics. It has been repeatedly suggested that a reservoir of SCCmec variants is being produced in CoNS and then transferred to $S$. aureus and other species [12].

Oliveira et al. [52] have also identified clones with $100 \%$ similarity that carried distinct SCCmec types, or clones with one resistant and one susceptible isolate. Interestingly, isolates belonging to the same PFGE type can carry up to three different combinations of the mec and ccr complexes and more than one SCCmec type, and several isolates can carry an SCCmec with multiple $c$ cr complexes. A large proportion of isolates can carry residual SCCmec. These observations indicate that the acquisition and loss of mobile genetic elements in S. epidermidis are probably very common, even in the community environment [13].

The high diversity of SCCmec in CoNS might be related to frequent events of genetic transference, such as packaging and transduction by a bacteriophage and conjugation events. Some studies have observed transduction of SCCmec and other elements between S. aureus strains [53]. Bacteriophage transduction was considered the main mechanism of horizontal gene transfer between staphylococci, given the scarcity of mobilization and conjugation loci in staphylococcal plasmids [54]. In the last decade, new mechanisms of transference of plasmids were identified and might play an important role in genetic transference of mobile elements such as SCCmec. They include conjugation mediated by integrative and conjugative elements (ICEs), also known as conjugative transposons [55], and in trans recognition of multiple variants of the canonic origin of transfer (oriT) by some conjugative plasmids [56].

The present results regarding SCCmec diversity in CoNS may be biased since two methodologies were used. The high frequency of non-typable elements in CoNS may indicate that the elements of these species are so different from those of $S$. aureus that these typing methods should not be applied to these microorganisms [33,57].

\section{Materials and Methods}

\subsection{Isolates}

A total of 299 strains were studied. Of these, 132 were isolated from blood cultures obtained from inpatients admitted to the University Hospital of the Botucatu Medical School, UNESP, from 1990 to 2012, and were stored in the Culture Collection of the Department of Chemical and Biological Sciences, Microbiology and Immunology Sector, Biosciences Institute, UNESP. In addition, 145 strains were isolated from nasal swabs of healthy individuals from the same community in Botucatu (Sao Paulo, Brazil), and 22 were isolated from chronic wounds of patients attending basic health units in Botucatu (Sao Paulo, Brazil) from 2011 to 2013. The swab and wound isolates were obtained during previous projects of our group and were stored in the bacteriology laboratory at $-80^{\circ} \mathrm{C}$. Sampling was designed in order to obtain the highest number of isolates from diverse staphylococcal species. 


\subsection{Identification of $\mathrm{CoNS}$}

The genus Staphylococcus was identified according to Baker [58] and Koneman et al. [59]. CoNS species were first identified by the simplified method proposed by Cunha et al. [60]. After DNA extraction with the Illustra kit (GE Healthcare) according to manufacturer instructions, the identification of strains was confirmed by the ITS-PCR technique using primers that target adjacent conserved sequences of the $16 \mathrm{~S}$ rRNA and $23 \mathrm{~S}$ rRNA genes [61]. The following reference strains were used for comparison of the results: $S$. epidermidis (ATCC 12228), S. haemolyticus (ATCC 29970), S. capitis subsp. capitis (ATCC 27843), S. capitis subsp. ureolyticus (ATCC 49325), S. warneri (ATCC 10209), S. hominis (ATCC 27844), S. hominis subsp. novobiosepticus (ATCC 700237), S. lugdunensis (ATCC 700328), S. saprophyticus (ATCC 15305), S. schleiferi subsp. schleiferi (ATCC 43808), S. sciuri subsp. sciuri (ATCC 29062), S. simulans (ATCC 27851), S. xylosus (ATCC 29979), and S. caprae (ATCC 35538). The standard strains were purchased from the American Type Culture Collection (ATCC, Manassas, VA, USA). The isolates showing discrepancy in the ITS-PCR band patterns were subjected to sequencing of the rpoB gene (nucleotides 1444-1928) [62].

\subsection{PFGE Typing}

PFGE typing was performed using a protocol modified from McDougal et al. [63]. The isolates were inoculated in BHI broth and incubated for $24 \mathrm{~h}$ at $37^{\circ} \mathrm{C}$. A $0.25 \mathrm{~mL}$ aliquot was centrifuged at 12,000 rpm for $50 \mathrm{~s}$. The supernatant was discarded and $150 \mu \mathrm{L}$ TE buffer (10 mM Tris, $1 \mathrm{mM}$ EDTA ( $\mathrm{pH}$ 8.0)) was added. This mixture was left in a water bath for $10 \mathrm{~min}$ at $37^{\circ} \mathrm{C}$. After vortexing, $2.5 \mu \mathrm{L}$ lysostaphin $(1 \mathrm{mg} / \mathrm{mL}$ in $20 \mathrm{mM}$ sodium acetate ( $\mathrm{pH} 4.5)$ ) and $150 \mu \mathrm{L}$ low melt agarose were added. The samples were added to plug molds, which were allowed to solidify. The plugs were transferred to $2 \mathrm{~mL}$ EC buffer (6 mM Tris- $\mathrm{HCl}, 1 \mathrm{M} \mathrm{NaCl}, 100 \mathrm{mM}$ EDTA, $0.5 \%$ Brij-58, 0.2\% sodium deoxycholate, $0.5 \%$ laurylsarcosyl sodium) and incubated at $37^{\circ} \mathrm{C}$ for at least $4 \mathrm{~h}$. The EC buffer was removed, and the plugs were washed four times in $2 \mathrm{~mL}$ TE for $30 \mathrm{~min}$ at room temperature. Onequarter of the plug was digested with $S m a \mathrm{I}$ in $50 \mu \mathrm{L}$ of restriction buffer. The plugs were transferred to $1 \%$ agarose gels prepared in $0.5 \times \mathrm{TBE}$ and covered with low melt agarose. Electrophoresis was performed at $6 \mathrm{~V} / \mathrm{cm}$ for $21 \mathrm{~h}$ at $14^{\circ} \mathrm{C}$. Running conditions were initial switch time $5 \mathrm{~s}$, final switch time $40 \mathrm{~s}$, running time $21 \mathrm{~h}$, voltage $6 \mathrm{~V} / \mathrm{cm}$. The comparison between gel patterns was made using UPGMA/Dice, tolerance $1.25 \%$, optimization $1 \%$, and similarity $80 \%$. The data were analyzed with the Bionumerics 7.1 software (Applied Maths, Sint-Martens-Latem, Belgium).

Since the $S$. hominis isolates were not properly restricted with SmaI, revealing patterns with fewer than 5 bands, the protocol of Bouchami et al. [32] based on restriction with XhoI was used. Running conditions were the following: block1-pulse times 2 to $20 \mathrm{~s}$, running time $11 \mathrm{~h}$; block 2 - pulse times 2 to $7 \mathrm{~s}$, running time $15 \mathrm{~h}$; voltage $6 \mathrm{~V}$; angle $120^{\circ}$. For S. hominis, UPGMA/Dice was also used, with $1 \%$ of tolerance and $0.8 \%$ optimization, using a cutoff similarity value of $80 \%$. The data were analyzed with the Bionumerics 7.1 software.

\subsection{SCCmec Typing}

SCCmec typing was performed by multiplex PCR using the primers described by Machado et al. [33] (Protocol 1). For isolates not typed by Protocol 1, the multiplex PCRs 1 and 2 described by Kondo et al. [64] (Protocol 2) were used. The SCCmec was defined as non-typable when (a) Protocol 1 showed no amplification product and (b) in Protocol 2 (b1) the $c c r$ complex exhibited no amplification product other than the mecA gene (286 bp), or (b2) the mec complex showed no amplification band, (b3) or the combination of $c \mathrm{cr} / \mathrm{mec}$ complexes determined an unknown SCCmec type. In the case of amplification of more than one fragment by Protocol 1, the isolate was considered to carry two SCCmec types.

\subsection{MLST}

MLST of S. epidermidis was performed according to Thomas et al. [65]. The following seven housekeeping genes were used: carbamate kinase $(\operatorname{arcC})$, shikimate dehydrogenase 
(aroE), ABC transporter ( $g t r)$, DNA mismatch repair protein (mutS), pyrimidine operon regulatory protein ( $p y r R)$, triosephosphate isomerase (tpiA), and acetyl coenzyme A acetyltransferase (yqiL). The PCR products were purified, precipitated, and sequenced in an ABI Prism 377 sequencer (Applied Biosystems). The Bionumerics Sequence Typing and MEGA 6.0 software were used to align the nucleotide sequences. The sequences were compared by database searches via the http: / / www.mlst.net website, accessed on 2 May 2021. The S. epidermidis sequence types were deposited in the MLST database (pubmlst.org, accessed on 2 May 2021).

\subsection{Diversity Index}

The Simpson diversity index was calculated as the number of strains per clonal profile according to Hunter and Gaston [66]. This index is defined as the probability of two unrelated strains originating from a given population being assigned to different groups.

\section{Conclusions}

The present study demonstrated the presence of CoNS clones circulating among hospital and community environments, especially S. lugdunensis and S. warneri isolates. Some PFGE types, such as S. haemolyticus, S. epidermidis, and S. capitis isolates, were restricted to one of the environments. The high diversity of SCCmec types within a clone suggests that SCCmec may not be a marker of the phylogenetic diversity of CoNS. The most prevalent species, S. epidermidis, exhibited STs associated with antimicrobial resistance and novel types [57].

Author Contributions: Conceptualization, L.P.-H. and M.d.L.R.d.S.d.C.; methodology, L.P.-H. and M.d.L.R.d.S.d.C.; validation, L.P.-H.; formal analysis, L.P.-H.; investigation, L.P.-H., D.F.M.R. and L.M.A.; resources, L.P.-H. and E.P.L.P.F.; data curation, L.P.-H.; writing-original draft preparation, L.P.-H.; writing-review and editing, L.P.-H. and M.d.L.R.d.S.d.C.; visualization, L.P.-H.; supervision, M.d.L.R.d.S.d.C.; project administration, L.P.-H. and M.d.L.R.d.S.d.C.; funding acquisition, M.d.L.R.d.S.d.C. All authors have read and agreed to the published version of the manuscript.

Funding: This work was supported by the National Council for Technological and Scientific Development (CNPq) Grant 303603/2020-8 and PROPG Edital 05/2021.

Institutional Review Board Statement: Not applicable.

Informed Consent Statement: Not applicable.

Data Availability Statement: The data presented in this study are contained within the article.

Acknowledgments: We thank the National Council for Technological and Scientific Development (CNPq) -Grant 303603/2020-8 and PROPG Edital 05/2021. This manuscript is part of the doctoral thesis "Pinheiro, L. (2018) Characterization of coagulase-negative staphylococci regarding clonal diversity and determinants of antimicrobial resistance. [Botucatu (SP)]: São Paulo State University".

Conflicts of Interest: The authors declare no conflict of interest.

\section{References}

1. Kloos, W.; Schleifer, K.H. Genus IV. Staphylococcus. In Bergey's Manual of Systematic Bacteriology; Sneath, P.H.A., Mair, N., Sharpe, M.E., Holt, J.G., Eds.; Williams \& Wilkins: Baltimore, MD, USA, 1986; pp. 1013-1035.

2. Otto, M. Staphylococcus epidermidis-The 'accidental' pathogen. Nat. Rev. Microbiol. 2009, 7, 555-567. [CrossRef]

3. Vos, P.; Garrity, G.; Jones, D.; Krieg, N.R.; Ludwig, W.; Rainey, F.A.; Schleifer, K.-H.; Whitman, W. The Firmicutes. In Bergey's Manual of Systematic Bacteriology, 2nd ed.; Springer: New York, NY, USA, 2010; p. 1450. [CrossRef]

4. Kloos, W.E.; Bannerman, T.L. "Staphylococcus and Micrococcus". In Manual of Clinical Microbiology, 6th ed.; Murray, P.R., Baron, E.J., Pfaller, M.A., Tenover, F.C., Yolken, R.H., Eds.; American Society Microbiology: Washington, DC, USA, 1999 ; pp. $264-282$.

5. Carroll, K.C.; Pfaller, M.A.; Landry, M.L.; McAdam, A.J.; Patel, R.; Richter, S.S.; Warnock, D.W. Manual of Clinical Microbiology, 12th ed.; ASM Press: Washington, DC, USA, 2019; p. 2832.

6. Michels, R.; Last, K.; Becker, S.L.; Papan, C. Update on Coagulase-Negative Staphylococci-What the Clinician Should Know. Microorganisms 2021, 9, 830. [CrossRef] [PubMed]

7. Heikens, E.; Fleer, A.; Paauw, A.; Florijn, A.; Fluit, A.C. Comparison of genotypic and phenotypic methods for species-level identification of clinical isolates of coagulase-negative staphylococci. J. Clin. Microbiol. 2005, 43, 2286-2290. [CrossRef] [PubMed] 
8. Barbier, F.; Ruppé, E.; Hernandez, D.; Lebeaux, D.; Francois, P.; Felix, B.; Ruimy, R. Methicillin-resistant coagulase-negative staphylococci in the community: High homology of SCCmecIVa between Staphylococcus epidermidis and major clones of methicillinresistant Staphylococcus aureus. J. Infect. Dis. 2010, 202, 270-281. [CrossRef] [PubMed]

9. Diekema, D.J.; Pfaller, M.A.; Schmitz, F.J.; Smayevsky, J.; Bell, J.; Jones, R.N.; Beach, M.; SENTRY Participants Group. Survey of infections due to Staphylococcus species: Frequency of occurrence and antimicrobial susceptibility of isolates collected in the United States, Canada, Latin America, Europe, and the Western Pacific region for the SENTRY Antimicrobial Surveillance Program, 1997-1999. Clin. Infect. Dis. 2001, 32, S114.

10. Ito, T.; Ma, X.X.; Takeuchi, F.; Okuma, K.; Yuzawa, H.; Hiramatsu, K. Novel type V staphylococcal cassette chromosome mec driven by a novel cassette chromosome recombinase, ccrC. Antimicrob. Agents Chemother. 2004, 48, 2637-2651. [CrossRef]

11. Du, X.; Zhu, Y.; Song, Y.; Li, T.; Luo, T.; Sun, G.; Yang, C.; Cao, C.; Lu, Y.; Li, M. Molecular analysis of Staphylococcus epidermidis strains isolated from community and hospital environments in China. PLoS ONE 2013, 8, e62742. [CrossRef]

12. Miragaia, M.; Thomas, J.C.; Couto, I.; Enright, M.C.; de Lencastre, H. Inferring a population structure for Staphylococcus epidermidis from Multilocus Sequence Typing Data. J. Bacteriol. 2007, 189, 2540-2552. [CrossRef]

13. Li, M.; Wang, X.; Gao, Q.; Lu, Y. Molecular characterization of Staphylococcus epidermidis strains isolated from a teaching hospital in Shanghai, China. J. Med. Microbiol. 2009, 58, 456-461. [CrossRef] [PubMed]

14. Miragaia, M.; Carriço, J.A.; Thomas, J.C.; Couto, I.; Enright, M.C.; de Lencastre, H. Comparison of molecular typing methods for characterization of Staphylococcus epidermidis: Proposal for clone definition. J. Clin. Microbiol. 2008, 46, 118-129. [CrossRef]

15. van der Mee-Marquet, N.; Achard, A.; Mereghetti, L.; Danton, A.; Minier, M.; Quentin, R. Staphylococcus lugdunensis Infections: High frequency of inguinal area carriage. J. Clin. Microbiol. 2003, 41, 1404-1409. [CrossRef] [PubMed]

16. Nicolosi, D.; Cinà, D.; Di Naso, C.; D’Angeli, F.; Salmeri, M.; Genovese, C. Antimicrobial Resistance Profiling of CoagulaseNegative Staphylococci in a Referral Center in South Italy: A Surveillance Study. Open Microbiol. 2020, 14, 91-97. [CrossRef]

17. Cherifi, S.; Byl, B.; Deplano, A.; Nonhoff, C.; Denis, O.; Hallin, M. Comparative epidemiology of Staphylococcus epidermidis isolates from patients with catheter-related bacteremia and from healthy volunteers. J. Clin. Microbiol. 2013, 51, 1541-1547. [CrossRef] [PubMed]

18. Bogado, J.; Limansky, A.; Sutich, E.; Marchiaro, P.; Marzi, M.; Putero, J.; Viale, A. Molecular characterization of methicillin-resistant coagulase-negative staphylococci from a neonatal intensive care unit. Infect. Control Hosp. Epidemiol. 2002, 23, 447-451. [CrossRef] [PubMed]

19. Rolo, J.; de Lencastre, H.; Miragaia, M. Strategies of adaptation of Staphylococcus epidermidis to hospital and community: Amplification and diversification of SCCmec. J. Antimicrob. Chemother. 2012, 67, 1333-1341. [CrossRef]

20. Nunes, A.P.; Teixeira, L.M.; Bastos, C.C.; Silva, M.G.; Ferreira, R.B.; Fonseca, L.S.; Santos, K.R. Genomic characterization of oxacillin-resistant Staphylococcus epidermidis and Staphylococcus haemolyticus isolated from Brazilian medical centres. J. Hosp. Infect. 2005, 59, 19-26. [CrossRef]

21. Martínez-Meléndez, A.; Morfín-Otero, R.; Villarreal-Treviño, L.; Camacho-Ortíz, A.; González-González, G.; Llaca-Díaz, J.; Rodriguez-Noriega, E.; Garza-González, E. Molecular epidemiology of coagulase-negative bloodstream isolates: Detection of Staphylococcus epidermidis ST2, ST7 and linezolid-resistant ST23. Braz. J. Infect. Dis. 2016, 20, 419-428. [CrossRef]

22. Mittal, G.; Bhandari, V.; Gaind, R.; Rani, V.; Chopra, S.; Dawar, R.; Sardana, R.; Verma, P.K. Linezolid resistant coagulase negative staphylococci (LRCoNS) with novel mutations causing blood stream infections (BSI) in India. BMC Infect. Dis. 2019, 19, 717. [CrossRef]

23. Kosecka-Strojek, M.; Sadowy, E.; Gawryszewska, I.; Klepacka, J.; Tomasik, T.; Michalik, M.; Hryniewicz, W.; Miedzobrodzki, J. Emergence of linezolid-resistant Staphylococcus epidermidis in the tertiary children's hospital in Cracow, Poland. Eur. J. Clin. Microbiol. Infect. Dis. 2020, 39, 1717-1725. [CrossRef]

24. Lozano, C.; Ruiz-García, M.; Gómez-Sanz, E.; López-García, P.; Royo-García, G.; Zarazaga, M.; Torres, C. Characterization of a cfr-positive methicillin-resistant Staphylococcus epidermidis strain of the lineage ST22 implicated in a life-threatening human infection. Diagn. Microbiol. Infect. Dis. 2012, 73, 380-382. [CrossRef]

25. Mendes, R.E.; Deshpande, L.M.; Farrell, D.J.; Spanu, T.; Fadda, G.; Jones, R.N. Assessment of linezolid resistance mechanisms among Staphylococcus epidermidis causing bacteraemia in Rome, Italy. J. Antimicrob. Chemother. 2010, 65, 2329-2335. [CrossRef] [PubMed]

26. Salgueiro, V.C.; Iorio, N.L.P.; Ferreira, M.C.; Chamon, R.C.; Santos, K.R.N. Methicillin resistance and virulence genes in invasive and nasal Staphylococcus epidermidis isolates from neonates. BMC Microbiol. 2017, 17, 15. [CrossRef] [PubMed]

27. Almeida, L.M.; Lincopan, N.; Araújo, M.R.E.; Mamizuka, E.M. Dissemination of the linezolid-resistant Staphylococcus epidermidis clone ST2 exhibiting the G2576T mutation in the $23 \mathrm{~S}$ rRNA gene in a tertiary-care hospital, Brazil. J. Antimicrob. Chemother. 2012, 67, 768-784. [CrossRef] [PubMed]

28. Sharma, P.; Satorius, A.E.; Raff, M.R.; Rivera, A.; Newton, D.W.; Younger, J.G. Multilocus Sequence Typing for interpreting blood isolates of Staphylococcus epidermidis. Interdiscip. Perspect. Infect. Dis. 2014, 787458. [CrossRef]

29. Takeuchi, F.; Watanabe, S.; Baba, T.; Yuzawa, H.; Ito, T.; Morimoto, Y.; Kuroda, M.; Cui, L.; Takahashi, M.; Ankai, A.; et al. Whole-genome sequencing of Staphylococcus haemolyticus uncovers the extreme plasticity of its genome and the evolution of human-colonizing Staphylococcal species. J. Bacteriol. 2005, 187, 7292-7308. [CrossRef] [PubMed]

30. Barros, E.M.; Ceotto, H.; Bastos, M.C.F.; dos Santos, K.R.N.; Giambiagi-deMarval, M. Staphylococcus haemolyticus as an Important Hospital Pathogen and Carrier of Methicillin Resistance Genes. J. Clin. Microbiol. 2012, 50, 166-168. [CrossRef] 
31. Yu, M.; Chen, Y.G.; Yu, Y.S.; Chen, C.L.; Li, L.J. Antimicrobial resistance and molecular characterization of Staphylococcus haemolyticus in a Chinese hospital. Eur. J. Clin. Microbiol. Infect. Dis. 2010, 29, 613. [CrossRef]

32. Bouchami, O.; Hassen, A.B.; de Lencastre, H.; Miragaia, M. Molecular epidemiology of methicillin-resistant Staphylococcus hominis (MRSHo): Low clonality and reservoirs of SCCmec structural elements. PLoS ONE 2011, 6, e21940. [CrossRef]

33. Machado, A.B.M.P.; Reiter, K.C.; Paiva, R.M.; Barth, A.L. Distribution of staphylococcal cassette chromosome mec (SCCmec) types I, II, III, and IV in coagulase-negative staphylococci from patients attending a tertiary hospital in southern Brazil. J. Med. Microbiol. 2007, 56, 1328-1333. [CrossRef]

34. Mendoza-Olazarán, S.; Morfin-Otero, R.; Rodríguez-Noriega, E.; Llaca-Díaz, J.; Flores-Treviño, S.; González-González, G.M.; Villarreal-Treviño, L.; Garza-González, E. Microbiological and molecular characterization of Staphylococcus hominis isolates from blood. PLoS ONE 2013, 8, e61161. [CrossRef]

35. Sousa, V.S.; Rabello, R.F.; Dias, R.C.S.; Martins, I.S.; Santos, L.B.G.S.; Alves, E.M.; Riley, L.W.; Moreira, B.M. Time-based distribution of Staphylococcus saprophyticus pulsed field gel-electrophoresis clusters in community-acquired urinary tract infections. Mem. Inst. Oswaldo Cruz. 2013, 108, 73-76. [CrossRef] [PubMed]

36. Widerström, M.; Wiström, J.; Ferry, S.; Karlsson, C.; Monsen, T. Molecular epidemiology of Staphylococcus saprophyticus isolated from women with uncomplicated community-acquired urinary tract infection. J. Clin. Microbiol. 2007, 45, 1561-1564. [CrossRef] [PubMed]

37. Poutanen, S.M. Staphylococcus lugdunensis: A notably distinct coagulase-negative Staphylococcus. Clin. Microbiol. News. Lett. 2001, 23, 147-150. [CrossRef]

38. Lourtet-Hascoët, J.; Bicart-See, A.; Félicé, M.P.; Giordano, G.; Bonnet, E. Staphylococcus lugdunensis, a serious pathogen in periprosthetic joint infections: Comparison to Staphylococcus aureus and Staphylococcus epidermidis. Int. J. Infect. Dis. 2016, 51, 56-61. [CrossRef]

39. Etienne, J.; Poitevin-Later, F.; Renaud, F.; Fleurette, J. Plasmid profiles and genomic DNA restriction endonuclease patterns of 30 independent Staphylococcus lugdunensis strains. FEMS Microbiol. Lett. 1990, 55, 93-97. [CrossRef] [PubMed]

40. Buttery, J.P.; Easton, M.; Pearson, S.R.; Hogg, G.G. Pediatric bacteremia due to Staphylococcus warneri: Microbiological, epidemiological, and clinical features. J. Clin. Microbiol. 1997, 35, 2174-2177. [CrossRef]

41. Shamoto, I.; Ishihara, Y.; Sato, A.; Usami, H.; Matsuda, N.; Ohta, M. Dissemination of Staphylococcus warneri in the Hair of ICU Doctors. Adv. Microbiol. 2015, 5, 599-603. [CrossRef]

42. Silva, G.D.I.; Justice, A.; Wilkinson, A.R.; Buttery, J.; Herbert, M.; Day, N.P.J.; Peacock, S.J. Genetic population structure of coagulase-negative staphylococci associated with carriage and disease in preterm infants. Clin. Infect. Dis. 2001, 33, 1520-1528. [CrossRef] [PubMed]

43. Al-Haqan, A.; Boswihi, S.S.; Pathan, S.; Udo, E.E. Antimicrobial resistance and virulence determinants in coagulase-negative staphylococci isolated mainly from preterm neonates. PLoS ONE 2020, 4, e0236713. [CrossRef]

44. Cui, B.; Smooker, P.M.; Rouch, D.A.; Daley, A.J.; Deighton, M.A. Differences between two clinical Staphylococcus capitis subspecies as revealed by biofilm, antibiotic resistance, and Pulsed-Field Gel Electrophoresis profiling. J. Clin. Microbiol. 2013, 51, 9-14. [CrossRef]

45. Delgado, S.; Arroyo, R.; Jiménez, E.; Marín, M.; del Campo, R.; Fernández, L.; Rodríguez, J.M. Staphylococcus epidermidis strains isolated from breast milk of women suffering infectious mastitis: Potential virulence traits and resistance to antibiotics. $B M C$ Microbiol. 2009, 9, 82. [CrossRef]

46. Bjorland, J.; Steinum, T.; Kvitle, B.; Waage, S.; Sunde, M.; Heir, E. Widespread distribution of disinfectant resistance genes among Staphylococci of bovine and caprine origin in Norway. J. Clin. Microbiol. 2005, 43, 4363-4368. [CrossRef]

47. Luiz, L.M.P.; Chuat, V.; Madec, M.N.; Araújo, E.A.; Carvalho, A.F.; Valence, F. Mesophilic lactic acid bacteria diversity encountered in Brazilian farms producing milk with particular interest in Lactococcus lactis strains. Curr. Microbiol. 2016, 73, 503. [CrossRef]

48. Garza-González, E.; López, D.; Pezina, C.; Muruet, W.; Bocanegra-García, V.; Muñoz, I.; Ramírez, C.; LLaca-Díaz, J.M. Diversity of staphylococcal cassette chromosome mec structures in coagulase-negative staphylococci and relationship to drug resistance. J. Med. Microbiol. 2010, 59, 323-329. [CrossRef]

49. Mørk, T.; Jørgensen, H.J.; Sunde, M.; Kvitle, B.; Sviland, S.; Waage, S.; Tollersrud, T. Persistence of staphylococcal species and genotypes in the bovine udder. Vet. Microbiol. 2012, 14, 171-180. [CrossRef] [PubMed]

50. Zeng, Z.L.; Wei, H.K.; Wang, J.; Lin, D.C.; Liu, X.Q.; Liu, J.H. High prevalence of $c f r$-producing Staphylococcus species in retail meat in Guangzhou, China. BMC Microbiol. 2014, 14, 151. [CrossRef] [PubMed]

51. John, M.A.; Pletch, C.; Hussain, Z. In vitro activity of quinupristin/ dalfopristin, linezolid, telithromycin and comparator antimicrobial agents against 13 species of coagulase-negative staphylococci. J. Antimicrob. Chemother. 2002, 50, 933-938. [CrossRef] [PubMed]

52. Oliveira, C.F.; Cavanagh, J.P.; Fredheim, E.G.; Reiter, K.C.; Rieger, A.; Klingenberg, C.; d'Azevedo, P.A.; Sollid, J.E. Coagulasenegative staphylococci in Southern Brazil: Looking toward its high diversity. Rev. Soc. Bras. Med. Trop. 2016, 49, 292-299. [CrossRef]

53. Mašlaňová, I.; Doškař, J.; Varga, M.; Kuntová, L.; Mužík, J.; Malúšková, D.; Růžičková, V.; Pantůček, R. Bacteriophages of Staphylococcus aureus efficiently package various bacterial genes and mobile genetic elements including SCCmec with different frequencies. Environ. Microbiol. Rep. 2013, 5, 66-73. [CrossRef] 
54. Ramsay, J.P.; Kwong, S.M.; Murphy, R.J.; Yui Eto, K.; Price, K.J.; Nguyen, Q.T.; O'Brien, F.G.; Grubb, W.B.; Coombs, G.W.; Firth, N. An updated view of plasmid conjugation and mobilization in Staphylococcus. Mob. Genet. Elem. 2016, 6, e1208317. [CrossRef]

55. Lee, C.A.; Thomas, J.; Grossman, A.D. The Bacillus subtilis conjugative transposon ICEBs1 mobilizes plasmids lacking dedicated mobilization functions. J. Bacteriol. 2012, 194, 3165-3172. [CrossRef]

56. O’Brien, F.G.; Yui Eto, K.; Murphy, R.J.; Fairhurst, H.M.; Coombs, G.W.; Grubb, W.B.; Ramsay, J.P. Origin-of-transfer sequences facilitate mobilisation of non-conjugative antimicrobial-resistance plasmids in Staphylococcus aureus. Nucleic Acids Res. 2015, 43, 7971-7983. [CrossRef]

57. Pinheiro, L. Characterization of Coagulase-Negative Staphylococci Regarding Clonal Diversity and Determinants of Antimicrobial Resistance. Ph.D. Thesis, São Paulo State University, Botucatu, SP, Brazil, 2018.

58. Baker, J.S. Comparison of various methods for differentiation of staphylococci and micrococci. J. Clin. Microbiol. 1984, 9, 875-879. [CrossRef] [PubMed]

59. Koneman, E.W.; Allen, S.D.; Janda, W.M.; Schreckenberger, P.C.; Winn, W.C., Jr. Koneman's Color Atlas and Textbook of Diagnostic Microbiology (Color Atlas and Textbook of Diagnostic Microbiology), 5th ed.; Lippincott: Philadelphia, PA, USA, 1997.

60. Cunha, M.L.R.S.; Sinzato, Y.K.; Silveira, L.V.A. Comparison of methods for identification of Coagulase-negative Staphylococci. Mem. Inst. Oswaldo Cruz. 2004, 99, 855-860. [CrossRef] [PubMed]

61. Couto, I.; Pereira, S.; Miragaia, M.; Sanches, I.S.; Lencastre, H. Identification of clinical staphylococcal isolates from humans by Internal Transcribed Spacer PCR. J. Clin. Microbiol. 2001, 39, 3099-3103. [CrossRef] [PubMed]

62. Mellmann, A.; Becker, K.; Eiff, C.; Keckevoet, U.; Schumann, P.; Harmsen, D. Sequencing and staphylococci identification. Emerg. Infect. Dis. 2006, 12, 333-336. [CrossRef] [PubMed]

63. McDougal, L.K.; Steward, C.D.; Killgore, G.E.; Chaitram, J.M.; McAllister, S.K.; Tenover, F.C. Pulsed-Field Gel Electrophoresis typing of oxacillin-Resistant Staphylococcus aureus isolates from the United States: Establishing a National Database. J. Clin. Microbiol. 2003, 41, 5113-5120. [CrossRef]

64. Kondo, Y.; Ito, T.; Ma, X.X.; Watanabe, S.; Kreiswirth, B.N.; Etienne, J.; Hiramatsu, K. Combination of multiplex PCRs for staphylococcal cassette chromosome mec type assignment: Rapid identification system for mec, ccr, and major differences in junkyard regions. Antimicrob. Agents Chemother. 2007, 51, 264-274. [CrossRef] [PubMed]

65. Thomas, J.C.; Vargas, M.R.; Miragaia, M.; Peacock, S.J.; Archer, G.L.; Enright, M.C. Improved Multilocus Sequence Typing scheme for Staphylococcus epidermidis. J. Clin. Microbiol. 2007, 45, 616-619. [CrossRef]

66. Hunter, P.R.; Gaston, M.A. Numerical index of the discriminatory ability of typing systems: An application of Simpson's index of diversity. J. Clin. Microbiol. 1988, 26, 2465-2466. [CrossRef] 